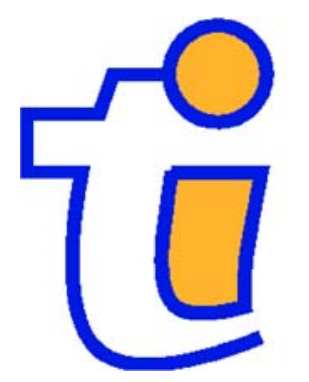

TI 2004-098/1

Tinbergen Institute Discussion Paper

Reciprocity and Emotions when Reciprocators know each other

Ernesto Reuben

Frans van Winden

Faculty of Economics and Econometrics, Universiteit van Amsterdam, and Tinbergen Institute. 
Tinbergen Institute

The Tinbergen Institute is the institute for economic research of the Erasmus Universiteit Rotterdam, Universiteit van Amsterdam, and Vrije Universiteit Amsterdam.

Tinbergen Institute Amsterdam

Roetersstraat 31

1018 WB Amsterdam

The Netherlands

Tel.: $\quad+31(0) 205513500$

Fax: $\quad+31(0) 205513555$

Tinbergen Institute Rotterdam

Burg. Oudlaan 50

3062 PA Amsterdam

The Netherlands

Tel.: $\quad+31(0) 104088900$

Fax: $\quad+31(0) 104089031$

Please send questions and/or remarks of nonscientific nature to driessen@tinbergen.nl.

Most TI discussion papers can be downloaded at http://www.tinbergen.nl. 


\title{
RECIPROCITY AND EMOTIONS WHEN RECIPROCATORS KNOW EACH OTHER*
}

\author{
Ernesto Reuben ${ }^{\#}$ and Frans van Winden ${ }^{\S}$
}

\begin{abstract}
This is an experimental study of a three-player power-to-take game where a take authority is matched with two responders. The game consists of two stages. In the first stage, the take authority decides how much of the endowment of each responder that is left after the second stage will be transferred to the take authority (the so-called take rate). In the second stage, each responder can react by destroying any part of his or her own endowment. Two treatments are considered: one in which all players are 'strangers' to each other (random matching), and one in which the responders know each other from outside the lab and are more or less close 'friends' (whereas the take-authority is again randomly selected). We focus on how the intensity of ties between responders impacts the decisions, beliefs, and emotions of both the responders and the take-authority. Some of our findings are: (1) although take rates are about the same, friends destroy more than strangers when faced with high take rates; (2) coordination on the same destruction level is stronger among friends; (3) the high level of coordination among friends can be explained by their emotional reaction towards one another; (4) the difference between the actual and expected take rate is a much better predictor of experienced emotions and destruction than the difference between the actual and (what is considered as) the fair take rate.
\end{abstract}

August 2004

JEL Classification Number: C72, C91, C92, H20, Z13, A10

Keywords: reciprocity, social ties, emotions, expectations, experiment, friends, principalagent relationship, appropriation, fairness.

\footnotetext{
* We are grateful for comments by participants at the Public Choice Society meeting in Baltimore, the ESA meeting in Amsterdam, and the Tilburg Symposium on Psychology and Economics.

* CREED, Department of Economics, University of Amsterdam, Roetersstraat 11, 1018 WB Amsterdam, The Netherlands; e-mail: e.reuben@uva.nl.

$\S$ CREED, Department of Economics, University of Amsterdam, Roetersstraat 11, 1018 WB Amsterdam, The Netherlands; e-mail: f.a.a.m.vanwinden@uva.nl
} 


\section{Introduction}

Over the last decade, various papers have emphasized the importance of emotions in decision making (e.g. Elster, 1998; Loewenstein, 2000). Emotions may help us explain behavior that is hard to reconcile with existing economic models. For example, Fehr and Gächter (2002) mention emotions as a possible explanation of non-strategic punishment in public good settings. If this were the case, emotion research could then be helpful in improving our understanding of the circumstances facilitating cooperation in social dilemma settings. Other studies have focused on the effects of emotions on preferences (Hirshleifer, 1987; Loewenstein, 1996), the value of emotions as producers of reliable signals (Frank 1987), the use of emotions as way of harnessing political support (Glaeser, 2004), and emotional hazard as a source of efficiency losses (van Winden, 2001). Others have proposed adaptations of utility functions reflecting emotions. For example, Erard and Feinstein (1994) assume that tax evasion causes disutility because of shame or guilt. Fehr and Schmidt (2000), in discussing the inequality aversion model, argue that individuals experience a disutility if their income is below the income of others because they may experience emotions such as envy.

However, the emotional aspects referred to in these models have not been directly tested empirically. There is very little research in economics that actually investigates which emotions are at stake in the situation of interest, and what precisely their impact is. If existing models would accurately describe observed behavior this would not be that important. Unfortunately, we have not yet reached this blissful state, as will be evidenced also by the results presented in this paper. Therefore, we think that a much greater effort in investigating the economic significance of emotions, taking seriously the findings of psychology and neuroscience, is warranted. A model based on an incorrect view may lead to incorrect conclusions. For instance, if the driving force behind an individual's decision to punish is anger but we incorrectly model it as envy, we will make wrong inferences regarding the action tendencies and other characteristics of the emotions at stake, and are consequently likely to make wrong predictions. In this case, for example, one might wrongly expect the individual to be in favor of some redistribution, instead of just opposing an intentional act (Lazarus, 1991), and further neglect that people may feel more anger in public than in private (Jakobs et al., 1996).

Recently, a number of experimental studies have begun to explicitly investigate the links between emotions and reciprocity in the ultimatum game and in the related power-to-take game (Sanfey et al., 2003; Ben-Shakhar et al., 2004; Bosman and van Winden, 2002; Bosman 
et al., 2004). They find substantial support for the economic significance of emotions, using various methods of measurement, and explain the responder's decision to negatively reciprocate as a tradeoff between the emotional satisfaction of punishing an unacceptable offer and the (more cognitive) reward of a monetary gain.

The main purpose of this paper is to extend this kind of analysis to cases where there are two instead of one responder in the power-to-take game, and where the responders either do or do not know each other. In this case, the proposer (the take authority) can make a claim on the resources of two instead of one responder, while each responder can destroy any part (including nothing and everything) of her own resources. Having multiple responders makes this game more realistic for social environments characterized by appropriation of which the power-to-take game captures important aspects, such as taxation, common agency or monopolistic selling (see Bosman and van Winden, 2002). For illustration, one might think of a tax authority selecting an income tax rate, while tax payers can destroy the income tax base (at a cost to themselves). Furthermore, we investigate whether knowing each other as responders affects the emotional and behavioral response.

The step from two to three responders is not at all trivial. On one hand, in the relationship between the proposer and a responder, two new factors are introduced that may affect the outcome of the game. First, if the benefit from punishing the proposer is independent of who does the punishing, an externality is introduced which opens up the opportunity to free ride with less punishment. Furthermore, the possibility of taking money from two instead of one responder makes the situation between the proposer and each of the responders considerably more unequal. If this triggers a more intense emotional response then more destruction could result.

On the other hand, the presence of a second responder introduces another set of considerations, namely, the relationship between the two responders. Responders may care for their relative payoffs, and in addition, they may also care for how they will feel about each other's behavioral response. In both cases, behavior may be affected by the belief of what the other responder is going to do. If a responder cares for relative payoffs, ${ }^{1}$ then her belief regarding the destruction decision of the other responder will determine whether her destruction increases or decreases the expected payoff difference between the two of them. This could lead to either more or less destruction. On the other hand, if a responder is

\footnotetext{
${ }^{1}$ As in the models of Levine (1998), Fehr and Schmidt (1999), Bolton and Ockenfels (2000), Falk and Fischbacher (2000), and Charness and Rabin (2002).
} 
concerned with how her action will be viewed by the other responder, then how much the other responder will destroy becomes, also from this perspective, a reference point for evaluating her decision. For example, if a responder destroys much less than the other, she might be seen as not standing up to unfair behavior, and conversely, if she destroys much more, she might be considered foolish for overreacting. A priori it is not clear what the behavioral consequences will be.

Beliefs and emotional responses are likely to be affected by the kind of relationship that exists between the responders. For example, people put different weights on the opinions of others depending on the type and strength of the relationship between them. We care more for what our close friends think of us than what a complete stranger might think. Furthermore, it is to be expected that individuals also differ in the importance assigned to payoff differences depending on who the other person is. It would be natural to expect, for instance, that a responder would mind more if a friend gets a lower payoff than if a stranger does. Unfortunately, there is little work on the effect of ties on the behavior of individuals in economic experiments. ${ }^{2}$ Hence, it is hard to predict the behavioral consequences of responders being friends instead of strangers. Since ties seem to play an important role in collective action (see Chong, 1991) and are potentially relevant in many economic situations (e.g. work environments), the issue whether and how they affect behavior is in fact of much wider interest. We have therefore decided to give it a prominent place in our experimental design.

The paper is organized as follows. In Section 2 we present the experimental design and link it to related studies. Section 3 describes the experimental procedures. Results are presented in Section 4. Section 5 discusses the main results in relation to the existing literature. Section 6 concludes.

\section{Design and Related Literature}

For our study we use a three-person version of the power-to-take game (Bosman and van Winden, 2002). In this one-shot game one subject, who can be considered as the 'take authority' (with endowment $E_{\text {take }}$ ), is matched with a pair of other subjects, the 'responders' (each with an endowment $E_{\text {resp }}^{i}$ where $i \in\{1,2\}$ indicates the responder). The game consists of two stages. In the first stage, the randomly chosen take authority decides on the 'take rate' $t_{i} \in[0,1]$, which is the part of responder $i$ 's endowment after the second stage that will be

\footnotetext{
${ }^{2}$ An exception being Abbink et al. (2002).
} 
transferred to the take authority. In the second stage, both responders decide simultaneously to destroy a part $d_{i}$ of their own endowment $E_{\text {resp }}^{i}$, with $d_{i} \in[0,1]$. For the take authority the payoff of the game equals her endowment plus the transfer from each of the responders, i.e. $E_{\text {take }}+t_{1}\left(1-d_{1}\right) E_{\text {resp }}^{1}+t_{2}\left(1-d_{2}\right) E_{\text {resp }}^{2}$, while responder $i$ 's payoff equals the part of her endowment that she does not destroy minus the amount transferred to the take authority, i.e. $\left(1-t_{i}\right)\left(1-d_{i}\right) E_{\text {resp }}^{i}$. In order not to introduce too many behavioral issues at a time, in our experiment take authorities can only select a uniform take rate (that is, $t_{1}=t_{2}=t$ ) and all endowments are equal $\left(E_{\text {resp }}^{1}=E_{\text {resp }}^{2}=E_{\text {take }}\right)^{3}$

To study the impact of responders knowing each other, the experiment consists of two treatments, one where responders are anonymous to each other ('strangers' treatment), and one where responders know each other ('friends' treatment). By comparing the results from the strangers treatment with earlier experiments involving only one responder, we can observe whether the presence of another responder appears to make a difference. By comparing the results from the strangers and friends treatments we can establish whether the existence of a tie between the responders makes a (further) difference. Furthermore, by using self-reports as research method for measuring emotions (Clore and Robinson, 2002) we can determine which emotions are important in these settings and analyze their explanatory value for observed behavior.

The simplicity of our design facilitates the study of the influence of emotions on behavior. First, each responder makes only one decision. This is useful since emotions can impact various decisions and it might be hard to disentangle which emotion influenced which decision. Second, responders cannot influence each other's monetary payoffs. Therefore, we are able to observe how a responder feels about the decision of the other responder without interference of any effect the other responder might have had on the first responder's income.

Our work is, on the one hand, related to studies exploring the economic significance of emotions and, on the other hand, to studies investigating how the presence of others affects decision-making. Although still small in number, there are some studies explicitly dealing with emotions to explain responder behavior in the kind of game investigated in this paper. However, they are all restricted to the one-proposer-one-responder case. A relatively early paper exploring this issue is Pillutla and Murnighan (1996). Responders in an ultimatum game experiment were asked, after each of a series of offers they had to accept or reject, to

\footnotetext{
${ }^{3}$ The power-to-take game differs in 3 important ways from the well known ultimatum game. First, in the powerto-take game each participant has an endowment. Second, in this game only the endowment of the responder(s) is at stake. And third, the responders can destroy any amount of their endowment.
} 
answer the open-ended question "How do you feel?" All offers were predetermined and afterwards a lottery selected one to determine actual payoffs. Answers to the feeling question were rated for expressions of the emotion of anger, and the rejection of offers was found to be related to this measure of anger. Their analysis also suggests that emotional reactions provide the critical link that determines when fairness perceptions tend to affect behavior. Bosman and van Winden (2002) introduced the power-to-take game with the specific purpose of investigating the importance of emotions for reciprocity in a situation of appropriation. In several experiments they also had responders self-report on their feelings, but now concerning a whole list of different emotions (positive as well as negative) and with 7-point scales for them to indicate the felt intensity of the respective emotion (see also Bosman et al., 2004; van Winden, 2001). In addition, they asked for responders' expectations (regarding the take rate). Their results show that the destruction of own resources by responders is related to the intensity of experienced negative emotions (particularly, contempt, irritation, and anger), which in turn is positively related to the actual take rate and negatively to the expected take rate.

Recently, for both games evidence has been found of a biological substrate for the negative reciprocity exhibited by responders. Sanfey et al. (2003), using fMRI of ultimatum game players, find that 'unfair' offers elicited activity in brain areas related to both emotion and cognition, and significantly heightened activity in an area related to emotions in case of rejection. ${ }^{4}$ Regarding the power-to-take game, Ben-Shakhar et al. (2004), using skin conductance as physiological measure of emotional arousal as well as self-reports, find that both self-reported anger and physiological arousal are related to destruction, with frustrated expectations playing an important and consistent role. Moreover, the self-reported measures of emotions appeared to be correlated with the physiological measures, which is reassuring for the use of self-reports in the study of reciprocity.

With this paper we hope to take the important next step in this line of research by studying what happens when a third person is introduced. In this respect, our work is related to papers on three-person ultimatum games. For instance, various authors have conducted experiments using ultimatum games that involve an inactive dummy player (Güth and van Damme, 1998; Kagel and Wolfe, 2001; Bereby-Meyer and Niederle, 2004). They find that responders seem to concentrate on their own as well as the proposers' payoffs and mostly

\footnotetext{
${ }^{4}$ In a similar study, Quervain et al. [2004] show that the effective punishment of norm violators produces activity in areas of the brain associated with the processing of rewards.
} 
ignore the welfare of the dummy players. Knez and Camerer (1995) use the strategy method to observe if a pair of responders playing with the same proposer condition their acceptance on the amount offered to the other responder. They find that about half of the responders will condition their response on the income the other responder would get. Riedl and Vyrastekova (2003) ran a three-person ultimatum game experiment in which they varied the effect the rejection of one responder has on the payoffs of another responder. They find that responders are more likely to reject proposals if this does not negatively affect their standing with respect to the other responder. All these experiments were not designed for an analysis of emotions and their explanatory value. Hence, important variables from that perspective, such as expectations, were not measured. Our experimental design is a first shot at exploring head-on the affective side of reciprocity in case of multiple potential reciprocators.

Psychological studies suggest that people may react quite differently emotionally to the same situation when others are present, and the more so if the other person is a friend rather than a stranger (see e.g. Jakobs et al., 1996; 1999). We want to explore the economic relevance of this literature by investigating whether the presence of another responder in the power-to-take game and the nature of the relationship between the responders has an effect not only on their emotional responses but also on their behavior and, furthermore, whether the emotional response is linked to behavior.

\section{Experimental Procedures}

The computerized experiment was run in October and November 2003 in the CREED laboratory of the University of Amsterdam. In total 177 subjects, almost all undergraduate students from the University of Amsterdam, participated in the experiment. About $45 \%$ of the subjects were students of economics. The other $55 \%$ were students from various fields such as biology, political science, law, and psychology. Subjects received a show-up fee of 5 euros, independent of their earnings in the experiment, and 10 euros as endowment. On average, subjects were paid out 13.34 euros (approximately 15.50 US dollars). The whole experiment took about one hour.

The experiment consisted of two treatments: a 'strangers' treatment, where the two responders in the game did not know each other, and a 'friends' treatment, where the responders knew each other. The recruitment of the subjects was done in a slightly different manner depending on the treatment. In the strangers treatment, subjects signed up individually for the experiment on a first-come-first-served basis. In the friends treatment, subjects were allowed to sign up only if they did so as a pair, that is, they had to provide the 
name of someone they knew and with whom they would take part in the experiment. If a subject signed up with someone else but nevertheless showed up alone to the experiment, (s)he was not allowed to participate. In this way we hoped to recruit subjects with ties. This approach, which is similar to the one used by Abbink et al. (2002), gives the opportunity to employ individuals with stronger bonds than one can establish in the laboratory. In an attempt to measure the strength of each pair's social tie, we asked each individual to describe the type of relationship they had with their partner and how frequently they saw each other.

After arrival in the lab's reception room, each subject drew a card to be randomly assigned to a seat in the laboratory. ${ }^{5}$ Once everyone was seated the instructions for the (oneshot) power-to-take game were read, followed by a few exercises to check the subjects' understanding of the procedures (a translation of the instructions is provided in Appendix 1). After these exercises the subjects were informed, by opening an envelope on their desk, which role (that of 'take authority' or 'responder') they had been assigned in the game. The game was framed as neutral as possible, avoiding any suggestive terms (like 'take authority', see Appendix 1). Subsequently, the subjects were randomly assigned into groups of three. In the strangers treatment complete anonymity was ensured since none of the members of the group knew who the other group members were. In the friends treatment, each group included a take authority and a pair of responders who signed up together for the experiment. Consequently, in this treatment anonymity was ensured between take authorities and responders but not between the responders themselves. In other words, take authorities knew that the responders in their group were people that came together to the experiment, but they did not know which responders they were. Similarly, responders knew that the other responder in their group was the individual with whom they came to the experiment whereas they did not know the identity of the take authority. The group assignment was clearly explained in the instructions.

Subjects then played the three-person power-to-take game via the computer. ${ }^{6}$ During the game, subjects were asked to fill out a few forms indicating not only their decisions but also how they felt, which take they expected, and which take rate they considered to be fair. Since in this paper we will concentrate on the responders' behavior, Figure 1 shows the precise order in which the responders' decisions, emotions and expectations were measured. Note that we asked subjects to report what they expected others to do before they observed their

\footnotetext{
${ }^{5}$ In order to keep track of the pairs of subjects who signed up together, in the friends treatment each pair drew a card containing the name of two seats.

${ }^{6}$ The experiment was programmed and conducted with the software z-Tree (Fischbacher, 1999).
} 
actual behavior. As in Bosman and van Winden (2002) subjects' emotions towards other players were measured through self-reports after the subject observed what the others did. We asked for the fair take rate, at the end, in the debriefing questionnaire.

Figure 1: Sequence of events for responders

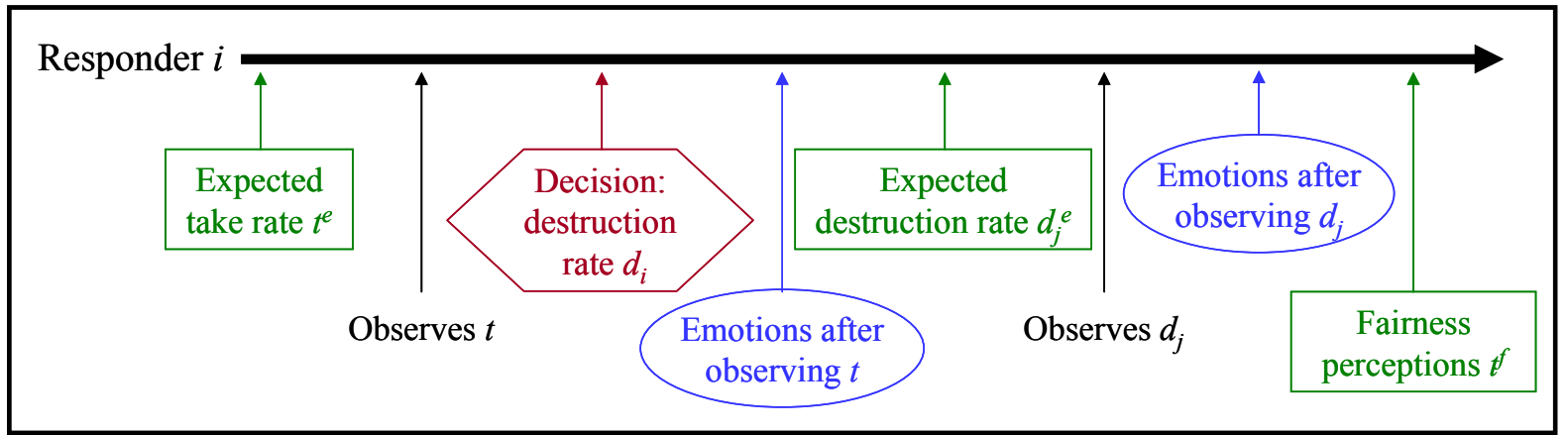

Expectations were measured by asking subjects to indicate the most likely value for $t$ or $d_{j}{ }^{7}$ In addition to the point estimate, we asked subjects to indicate on a 7-point scale how confident they were of their expectation. Emotions were measured by providing subjects with a list of fourteen emotion names and asking them to report on a 7-point scale with what intensity they experienced each emotion. The scale ranged from "no intensity at all" (1) to "very intensely" (7). The list included the following emotions: pride, envy, anger, guilt, joy, shame, irritation, gratitude, surprise, contempt, disappointment, admiration, regret and sadness. A variety of emotions were included to avoid pushing subjects in a particular direction.

\section{Results}

In this section we present and analyze the decisions that were taken and the emotions that subjects experienced. Furthermore, we investigate whether the reported emotions help explain the behavior of the responders in both treatments. A summary of the individual data is provided in Appendix 2.

\section{Observed behavior}

On average, the take rate was $60.5 \%(62.3 \%)$ in the strangers (friends) treatment. The median take rate was $60 \%$ in both treatments. Interestingly, these take rates are very similar to the

\footnotetext{
${ }^{7}$ We decided to measure expectations in this way since subjects might have difficulty in reporting a probability distribution of a continuous variable (over the interval $[0,1]$ ).
} 
ones reported for comparable one-responder power-to-take games. ${ }^{8}$ The similarity between the take rates in both treatments leads to our first result.

\section{RESULT 1: Take rates do not differ between the friends and strangers treatment.}

Support: Using Robust-Rank-Order ${ }^{9}$ (RRO) and Kolmogorov-Smirnov tests, the hypothesis that the take rates are drawn from the same distribution cannot be rejected $(p=0.99$ and $p=$ 0.79 , respectively). ${ }^{10}$

Turning now to the responders, in both treatments a considerable number of responders destroyed some or all of their endowment. In the strangers (friends) treatment $31.3 \%(40.0 \%)$ of the responders destroyed a positive amount. In total, responders in the strangers (friends) treatment destroyed on aggregate $18.4 \%(29.4 \%)$ of their endowment. For both measures, these results are respectively below (strangers treatment) and above (friends treatment) the ones obtained for the one-responder game. ${ }^{11}$ The difference in destruction between strangers and friends is even starker if we concentrate on responders who faced high take rates, that is, take rates that are equal to or above the median take rate. ${ }^{12}$ This leads us to our second result.

RESULT 2: When facing high (above median) take rates friends destroy more and more frequently than strangers.

Support: Of the responders who faced a take rate that was equal to or higher than the median take rate, strangers destroyed on aggregate less than friends, namely $25.8 \%$ vs. $53.6 \%$ (RRO test, $p<0.02$ ). Moreover, only $43.3 \%$ of the strangers destroyed some of their endowment whereas $66.7 \%$ of friends decided to do so (RRO test, $p<0.10$ ). This result is partly driven by the fact that friends are more likely to destroy all of their endowment than strangers:

\footnotetext{
${ }^{8}$ Bosman et al. (2004) report an average and median take rate of $60 \%$.

${ }^{9}$ The Robust Rank Order test (Fligner and Policello, 1981) is a modification of the Wilcoxon-Mann-Whitney test, designed to be appropriate in more situations. It has similar power and seems to perform better than the Wilcoxon-Mann-Whitney test (Feltovich, 2003).

${ }^{10}$ All tests in this paper are two-sided.

${ }^{11}$ In Bosman et al. (2004) $37.5 \%$ of the responders destroyed a positive amount, while on aggregate $24.70 \%$ of the endowment was destroyed.

${ }^{12}$ As our main interest is in destruction behavior, concentrating on take rates above or equal to the median makes sense since most of the destruction, $91.85 \%$ to be precise, occurs at these high take rates.
} 
$24.3 \%$ of the friends destroyed everything while only $10.4 \%$ of the strangers did so (RRO test, $p<0.05){ }^{13}$

Results 1 and 2 suggest that, whereas at high take rates friends are likely to destroy more and more frequently than strangers, the behavior of take authorities does not depend on whether they are facing a pair of friends or a pair of strangers. This can be further substantiated by looking at the earnings of the take authorities. In the strangers treatment, take authorities choosing a high take rate earned on average 3.13 euros more than take authorities who chose a low take rate. They also faced more risk, however, in the sense of a higher variance in earnings. In contrast, in the friends treatment, take authorities who chose a high take rate earned on average 2.01 euros less than those choosing a low take rate, even though they too faced a larger variation in earnings. Hence, while in the strangers treatment it might make sense to choose a high take rate and risk some variation in income, in the friends case this is clearly an inferior choice. Nevertheless, it turns out that the proportion of take authorities choosing a high take rate is roughly the same in both treatments.

\section{Determinants of behavior}

To investigate what is motivating a responder to destroy, we estimated a multivariate probit model for the probability of destruction, using as explanatory variables: demographic data (gender and area of study), the take rate, the expected take rate, the perceived fair take rate, and treatment dummies. In addition, we checked for interaction between the explanatory variables and used any significant interaction term. The following result is obtained (see Table 6 in Appendix 3).

RESULT 3: The probability of destruction is positively related to the take rate and to the difference between the actual and the expected take rate, and is lower for females.

Support: Judged by the signs of the significant coefficients $(p<0.05)$, it appears that responders who are likely to destroy some or all of their endowment are responders who: faced high take rates, experienced large positive differences between the take rate and their

\footnotetext{
${ }^{13}$ It would certainly be of interest to know if the strength of the social tie between responders has an effect on destruction. Unfortunately, we have very little variation in the two variables used to measure the strength of social ties, and hence, we cannot make a meaningful analysis. Roughly $60 \%$ of all pairs reported their type of relationship as a "friendship" while the other $40 \%$ was evenly distributed among four categories. Similarly, $60 \%$ of all pairs reported their frequency of contact as "very frequent" while the other $40 \%$ was evenly distributed among three categories.
} 
expected take rate, and are male. Furthermore, friends have a bigger coefficient than strangers for the influence of the take rate on the probability of destruction. This mirrors our previous result where we found that friends destroy more frequently than strangers when faced with high take rates. Contrary to what one would expect given the emphasis on fairness in the literature, but in line with the findings of Pillutla and Murnighan (1996), the variable measuring the difference between the actual take rate and the fair take rate does not show up as a significant determinant of destruction. ${ }^{14}$

\section{Experienced Emotions}

The intensity scores of emotions reveal that subjects experienced a variety of emotions. Concentrating on how emotions influenced the destruction decision gives us a clear result.

RESULT 4: The probability of destruction is positively (negatively) related to the intensity of experienced negative (positive) emotions.

Support: We estimated a probit model for each emotion separately, with the probability of destruction as the dependent variable. The resulting coefficients and their level of significance are presented in Table 1.

Table 1: Coefficients of probit regressions with destruction as the dependent variable

\begin{tabular}{|c|c|c|}
\hline Explanatory variable & Strangers & Friends \\
\hline disappointment & $0.311^{* *}$ & $0.267^{* *}$ \\
gratitude & $-0.260^{*}$ & $-0.473^{* *}$ \\
contempt & $0.226^{*}$ & $0.330^{* *}$ \\
anger & $0.231^{*}$ & $0.291^{* *}$ \\
irritation & $0.198^{*}$ & $0.314^{* *}$ \\
joy & $-0.235^{*}$ & $-0.377^{* *}$ \\
envy & $0.337^{* *}$ & 0.067 \\
admiration & -0.079 & $-0.480^{* *}$ \\
sadness & 0.188 & $0.228^{*}$ \\
shame & 0.303 & 0.119 \\
pride & 0.129 & 0.103 \\
guilt & 0.071 & -0.019 \\
regret & 0.064 & 0.118 \\
surprise & -0.018 & 0.075 \\
\hline
\end{tabular}

\footnotetext{
${ }^{14}$ Due to a significant correlation between the expected take rate and the fair take rate we cannot completely rule out the role of fairness. However, running the probit regression with the difference between the actual and the fair take included but excluding the difference between the actual and the expected take rate, does not make the former variable significant.
} 
** Significant at 1 percent level. * Significant at 5 percent level.

The table shows that, in both treatments, similar negative (as well as positive) emotions are involved in destruction behavior. RRO tests give further support for this finding: in both treatments, responders who destroyed reported significantly higher intensities of anger, irritation, contempt, and disappointment, and significantly lower intensities of joy, and gratitude $(p<0.10)$. Furthermore, for any of the abovementioned emotions, we cannot find any significant difference in the intensity scores between the two treatments (for both responders who destroyed and responders who did not destroy).

Having found that destruction is related to experienced emotions, the question arises what explains the different emotional responses. To answer this question we estimated a multivariate ordered probit model, with the intensity of different positive and negative emotions as the dependent variable. For the analysis we concentrated on the emotions that turned out to be good predictors of destruction (i.e. disappointment, contempt, anger, irritation, envy, sadness, gratitude, joy, and admiration). Again, we used as explanatory variables: demographic data (gender and area of study), take rate, expected take rate, perceived fair take rate, and treatment dummies. In addition, any significant interaction term was included. The following result is obtained.

RESULT 5: The intensity of negative (positive) emotions is positively (negatively) related to the take rate and to the difference between actual and expected take rates.

Support: All negative (positive) emotions that are good predictors of destruction in both treatments, show a positive (negative) relationship with the take rate $(p<0.05)$. The same holds true for the difference between the take rate and the expected take rate $(p<0.05)$. For illustration, in Table 7 in Appendix 3 we present the results of one such regression. In this regression we used as dependent variable the average of the three anger-like emotions: anger, irritation, and contempt. The regression also shows a gender effect. It appears that female subjects are more likely to report lower intensities of negative emotions. ${ }^{15}$

\footnotetext{
${ }^{15}$ In the regressions of individual emotions we find that women are more likely to report lower intensities of anger and irritation, and higher intensities of gratitude. However, we also find that women show a stronger reaction to differences between the take rate and the expected take rate in the regressions for disappointment, irritation, gratitude and joy. Hence, it appears that we have a mixed outcome when it comes to gender. Women report on average lower (higher) intensities of negative (positive) emotions, but this difference seems to disappear if the take rate is higher than expected.
} 
Summarizing, the same variables that are good predictors of destruction behavior (see Result 3) are also good predictors of the intensities of experienced emotions. In combination with the finding that emotions are good predictors of destruction, this suggests the following intuitive explanation for destruction: the higher the take rate and the larger the difference between the take rate and the expected take rate, the stronger the intensity of anger-like emotions experienced by a responder, which in turn makes it more likely that (s)he will destroy in order to punish the take authority. These findings are consistent with, but strengthen and extend, those obtained for the one-responder power-to-take game.

Further evidence that is easily explained with an emotion-driven account of destruction (but is hard to explain otherwise) is the time responders take to make their decision. In our experiment, responders that destroyed a positive amount not only reported higher intensities of negative emotions; they also took more time to decide (RRO test, $p<0.10$ ). However, if we concentrate on responders who destroyed everything, we find that although they reported the highest intensities of negative emotions (RRO test, $p<0.01$ ), they did not take more time to make a decision than responders who did not destroy (RRO test, $p=0.38$ ). In other words, the slowest responders turn out to be those who reported intermediate intensities of negative emotions and destroyed intermediate amounts. Traditional theories in economics gives us no reason to think why making the decision to destroy requires more time than making the decision not to destroy. However, research on emotions suggests the following. At low intensities of negative emotions a decision can take little time because there is no real conflict between the (cognitive) interest to earn as much money as possible and the (emotional) urge to punish the proposer. At higher intensities, this conflict does arise and hence one would expect subjects to take more time in order to sort it out. However, if the intensity of the negative emotions becomes very high it can push subjects over a threshold beyond which they are less prone to think and simply follow the emotion's action tendency, which entails less time to reach a decision (Frijda, 1986; Frijda, 1988; Goleman, 1995).

Nevertheless, there is an important aspect of the data that is not explained by the emotional reaction of responders towards proposers. Result 5 indicates that friends and strangers are equally angry and unhappy at high take rates. However, as was pointed out in Results 2 and 3, at high take rates friends destroy more and more frequently than strangers. A more detailed look at the data reveals that the disparity between destruction and anger is 
caused by the fact that angry strangers appear to destroy less frequently and smaller amounts than angry friends. ${ }^{16}$ This can be observed in Figure 2.

As can be seen in the figure, in both treatments the ratio of non-angry and angry responders is roughly the same ( 2 to 1 for strangers and 2.33 to 1 for friends). Moreover, the frequency of destruction among non-angry responders is almost identical $(25.0 \%$ for strangers vs. $26.5 \%$ for friends). However, the frequency of destruction among angry responders is considerably different: whereas only $43.8 \%$ of the angry strangers destroyed something, $71.4 \%$ of angry friends decided to do so. If we look at the amounts destroyed we also find a difference. On aggregate, angry strangers destroyed $29.3 \%$ of their endowment while angry friends destroyed $68.6 \%$.

Figure 2: Destruction by angry and non-angry responders

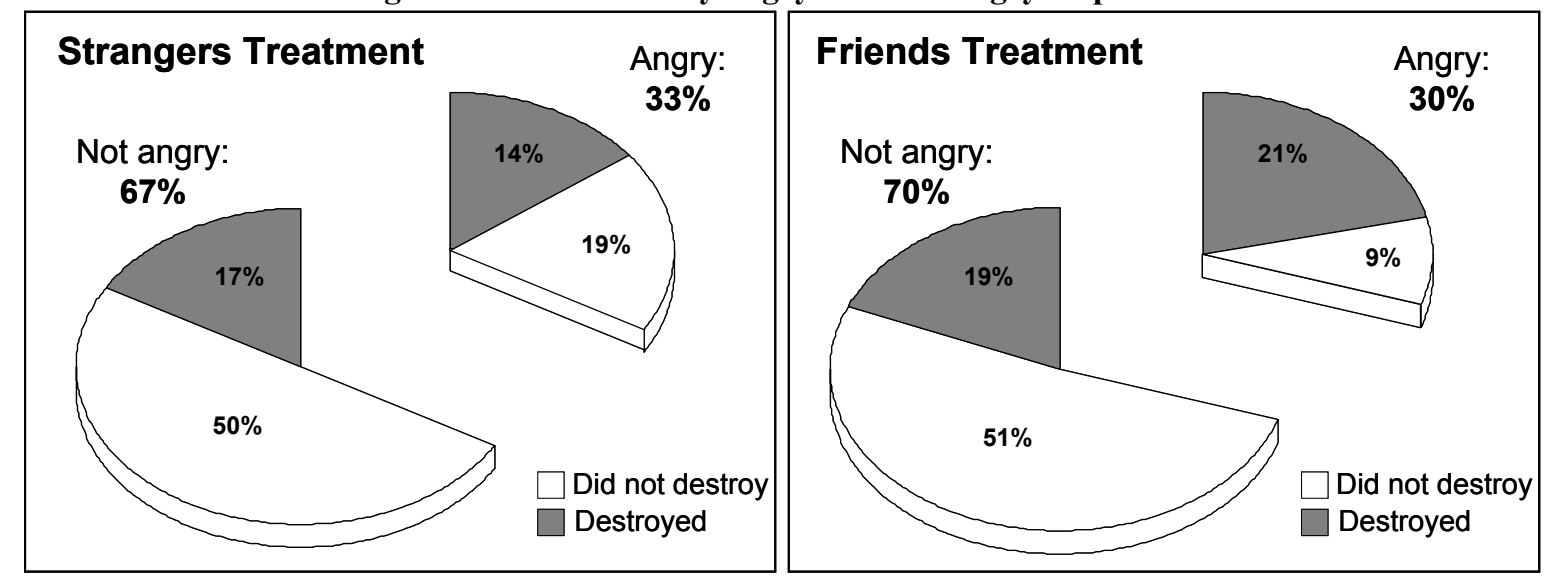

\section{Coordination}

In order to explain this difference, we further analyze the behavior and emotional response of the responders. What we are interested in is to see whether pairs of friends behaved markedly different than pairs of strangers. The following results are obtained.

RESULT 6: Overall, responders coordinate less often than they expect; however, friends are better at coordinating destruction than strangers.

Support: Most responders expected the other responder to choose a similar destruction rate ${ }^{17}$ ( $77.1 \%$ of the strangers and $78.6 \%$ of the friends). However, their expectation was incorrect in a significant number of cases $(32.4 \%$ of the strangers and $29.1 \%$ of the friends, RRO tests,

\footnotetext{
${ }^{16}$ We classified subjects as angry if they reported an average intensity of 5 or more (on the 7-point scales) for anger, irritation and contempt.

${ }^{17}$ For the numbers reported here, a deviation of up to plus or minus $10 \%$ was allowed. However, the same statistically significant differences are found using other cut-off points (specifically: $20 \%, 5 \%$, and $0 \%$ ).
} 
$\mathrm{p}<0.01)$. Concentrating on the responders who destroyed, a similar pattern is obtained: $60.0 \%$ of the strangers and $67.9 \%$ of the friends expected the other responder to choose a similar destruction rate. However, they were incorrect $77.8 \%$ of the time in the case of strangers and $36.8 \%$ of the time in the case of friends. From these numbers, it is evident that, although in both treatments responders who destroyed seriously overestimated the similarity between destruction rates, friends are better than strangers at coordinating on positive destruction rates (RRO tests, $\mathrm{p}<0.05$ ). There are no significant differences between treatments if we look at responders who did not destroy.

This result can also be observed if we look at the differences between the correlation coefficients of the destruction rates. Among subjects that destroyed, the correlation coefficient regarding their own destruction rate and the destruction rate they expected of the other responder ( 0.557 for strangers and 0.785 for friends) was significantly higher $(p<0.10)$ than the correlation coefficient concerning the actual destruction rates of the pairs of responders ( -0.067 for strangers and 0.505 for friends). Furthermore, the correlation between the actual destruction rates of the pairs of responders was significantly higher in the friends treatment $(p<0.01)$.

To a great extent, the stronger coordination among friends who destroyed occurred when responders destroyed all or almost all of their endowment. To illustrate, first consider the pairs of responders where at least one subject destroyed $90 \%$ or more: in the friends treatment $17.1 \%$ of all pairs fit this criterion whereas in the strangers treatment the corresponding number is $25.0 \%$. Now, consider the percentage of these pairs where both responders destroyed at least 90\%: in the friends treatment this percentage is $50 \%$ whereas in the strangers treatment it is $0 \%$. Thus, in the strangers case there was not a single pair in which both responders simultaneously destroyed (almost) all of their endowment. The next result provides an explanation based on differences in emotional responses.

RESULT 7: The emotional response towards the other responder facilitates the coordination of destruction among friends but not among strangers.

Support: To back up this result we compare differences in emotional intensity scores across two sets of responders. ${ }^{18}$ The first set consists of responders that destroyed more than the responder they were paired with. For convenience, we will call them the 'punishers'. The

\footnotetext{
${ }^{18}$ Since we are interested in explaining the difference between friends and strangers, we concentrate on the emotions that exhibited significantly different patterns across treatments, namely: pride, anger, joy, irritation, gratitude, disappointment, and sadness.
} 
second set consists of responders who destroyed less than the other responder, which will be labeled the 'acquitters', for short. In the strangers treatment, punishers reported more anger, irritation, sadness, and disappointment than acquitters (RRO tests, $p<0.10$ ). Given this negative emotional response, it stands to reason that strangers (anticipating this response) would prefer to be among the acquitters rather than the punishers. In remarkable contrast, in the friends treatment punishers reported similar emotional intensities as acquitters for all the abovementioned emotions (RRO tests, $p>0.10$ ). Hence, given the choice, friends unlike strangers might be indifferent between being a member of either of the two sets of responders. Further support is obtained if we compare acquitters with those paired responders that destroyed the same amount: the 'coordinators'. In the friends treatment, acquitters reported, on the one hand, more anger, irritation, and disappointment and, on the other hand, less pride, joy, and gratitude, than coordinators (RRO tests, $p<0.10$ ). Therefore, given the choice, (anticipating) friends would presumably prefer to be coordinators rather than acquitters. In contrast, in the strangers treatment, acquitters reported similar emotional intensities as coordinators for all these emotions (RRO tests, $p>0.10$ ). Thus, from this point of view, strangers would be indifferent between being a coordinator and being an acquitter.

Summarizing, in view of the just discussed differences in emotional responses between responders, destroying seems to be more risky for strangers than for friends since it might leave them in the 'punisher' position inducing additional negative emotions. This may explain why, even when very angry, strangers often decide not to destroy. Friends, on the other hand, experience additional positive emotions if they coordinate on the same destruction rate. Consequently, angry friends may be much more inclined to destroy, especially if they believe that the other responder will also destroy. ${ }^{19}$ This is supported, or at least not challenged, by the finding that on average angry friends who did not destroy expected others to destroy only $16.7 \%$ of their endowment, while angry friends who destroyed everything expected others to destroy $96.2 \% .^{20}$

\footnotetext{
${ }^{19}$ Furthermore, since coordination on a destruction rate of $100 \%$ may be easier (more focal) than coordinating on an intermediate destruction rate, this may explain why friends appear to be more inclined to destroy everything.

${ }^{20}$ While this is a clear difference (significant at $p<0.01$, RRO test), in the strangers case, the same calculation does not yield a clear-cut result. Specifically, angry strangers who did not destroy expected others to destroy $31.1 \%$ of their endowment, while angry strangers that destroyed everything expected others to destroy $52.9 \%$. This difference is not only smaller but also not significant (RRO test, $p=0.30$ ).
} 
However, we should also discuss a potentially alternative explanation of destruction behavior. Since in our experiment friends had the possibility of interacting after the experiment, side payments were possible. So, one could perhaps argue or conjecture that the stronger coordination among friends who destroy is due to these side payments and not because of any differences in emotional responses. We have not succeeded ourselves in finding a convincing explanation, side-stepping emotions, in which side payments may lead to more coordination among responders. Nonetheless, in order to test if side payments played a role, we asked subjects in the debriefing questionnaire, first, if they intended to share their earnings after the experiment, and, second, if the possibility of sharing earnings after the experiment affected their decision. If side payments would indeed boost coordination one would expect more coordination among responders who answered positively to one or both of the abovementioned questions. However, we find no significant difference in coordination between those who answered positively or negatively to any of these two questions. This is also true if we concentrate on angry responders, that is, the responders who acted noticeably different across the two treatments (RRO tests, $p=0.78$ and $p=0.55$, respectively). Hence, we tentatively conclude that although side payments were possible they played no significant role in the game.

\section{Expected take rates and fairness perceptions}

Expectations about the take rate turned out to have an important influence on the intensity of emotions and destruction behavior. This is further illustrated by Figure 3. Responders are divided into two groups: 'optimists', that is, people who expected a lower take rate than the one they faced (observations above the diagonal), and 'pessimists', who expected a higher take rate than the one they faced (observations below the diagonal). It is easy to see from the figure that destruction, and especially high destruction (more than 50\%), is carried out almost exclusively by 'optimists'. ${ }^{21}$ A plausible explanation is that, first, subjects form an expectation of what the average take authority will do and, then, judge the degree of (un)kindness of the take authority by the deviation from this reference point. Negative deviations are judged as unkind and are punished by destruction.

\footnotetext{
${ }^{21}$ Of the responders who destroyed (more than 50\%) 74.4\% (83.3\%) are optimists.
} 
Figure 3: Scatter plot of actual and expected take rates

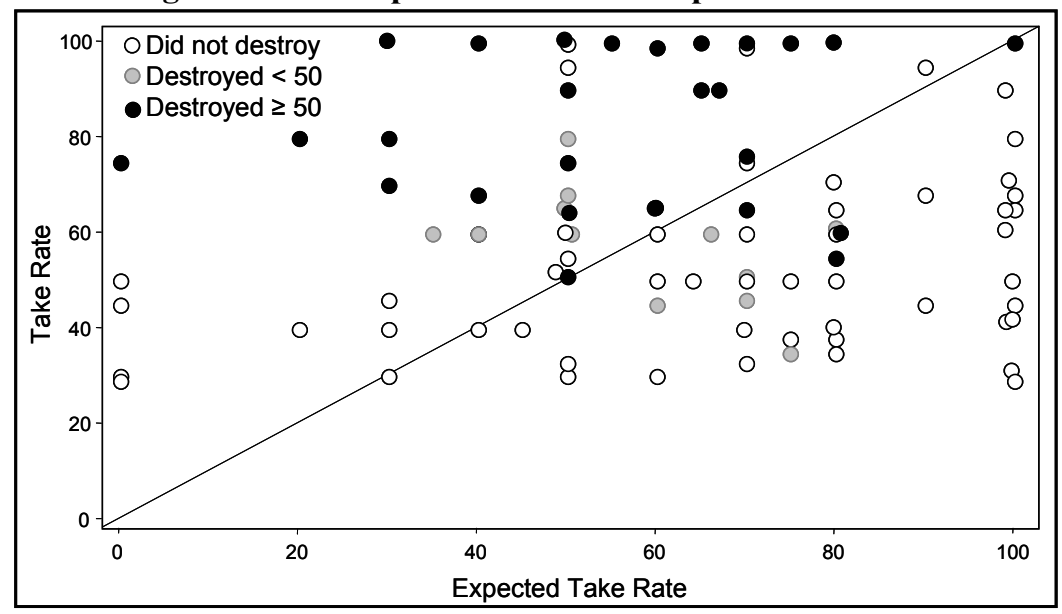

Instead of using as reference point the expectation of what the take authority will do, a responder may (also) use what he thinks the take authority should do, that is, use as reference point a take rate that is considered to be fair. However, as noted in the discussion of Result 3 , unlike the expected take rate the responder's fair take rate is not clearly related to destruction.

Comparing responders who experienced an above average difference between take rate and fair take rate with responders who experienced a below average difference between these take rates, we find that a majority of the responders that destroyed faced an above average difference (both treatments). However, it is likely that responders who faced an above average difference between take rate and fair take rate also faced above average take rates. Hence, more destruction might simply reflect a reaction to high take rates. As it turns out, this is indeed the case. Once we control for the effect of the take rate, responders that experienced an above average difference between the take rate and the fair take rate did not destroy significantly more often than responders who experienced a below average difference. This can be seen from Table 2 where we control for the effect of the take rate on the frequency of destruction by looking only at a limited range of take rates (more specifically, take rates in the third quartile). ${ }^{22}$

Table 2: Frequency of destruction and differences between actual, fair, and expected take rates

\begin{tabular}{|cccc|}
\hline & $\begin{array}{c}\text { Fair Take } \\
\text { Rate }\end{array}$ & $\begin{array}{c}\text { Expected } \\
\text { Take Rate }\end{array}$ & $\begin{array}{c}\text { Frequency of } \\
\text { destruction }\end{array}$ \\
\hline $\begin{array}{c}\text { Above average difference between } \\
\text { take rate and fair take rate }\end{array}$ & $10.7 \%$ & $69.3 \%$ & $47.4 \%$ \\
$(12.5)$ & $(21.0)$ & $(51.3)$ \\
\hline
\end{tabular}

\footnotetext{
${ }^{22}$ We used the third quartile in order to have a good mix of responders who destroyed and responders who did not destroy. In the top quartile most people destroyed while in the first two quartiles there was very little destruction.
} 


\begin{tabular}{|cccc|}
\hline $\begin{array}{c}\text { Below average difference between } \\
\text { take rate and fair take rate }\end{array}$ & $\begin{array}{c}47.4 \% \\
(17.0)\end{array}$ & $\begin{array}{c}72.6 \% \\
(25.8)\end{array}$ & $\begin{array}{c}29.4 \% \\
(47.0)\end{array}$ \\
\hline Above average difference between & $25.5 \%$ & $48.4 \%$ & $62.5 \%$ \\
take rate and expected take rate & $(20.2)$ & $(9.3)$ & $(50.0)$ \\
\hline Below average difference between & $30.0 \%$ & $88.8 \%$ & $20.0 \%$ \\
take rate and expected take rate & $(26.4)$ & $(12.4)$ & $(41.0)$ \\
\hline
\end{tabular}

Data for take rates between 60 and 74, and both treatments. Numbers in brackets are standard deviations.

Although responders who experienced an above average difference between take rate and fair take rate still destroyed more frequently than the rest, this difference is not significant (RRO test, $p=0.29$ ). In contrast, if we do the same calculation for the difference between the take rate and the expected take rate, we find a significantly higher frequency of destruction among responders who experienced an above average difference (RRO test, $p<0.02$ ). ${ }^{23}$

Consequently, it appears that deviations from the expected take rate are much more important than deviations from the fair take rate. This is the case even though it is argued that equity considerations are especially important in highly asymmetric situations with complete information (Smith, 1976; Fehr et al., 1993). This is not to say that fairness perceptions do not play a role in the responders' decision-making. It may be that fairness plays a more indirect role than usually envisaged. Suggestive in this respect is the following analysis of the relationship between the fair take rate and the expected take rate. Focusing on the difference between the expected take rate and the fair take rate shows that in only $3.4 \%$ of the cases this difference was negative. In other words, the overwhelming majority of responders expected a higher take rate than the one they considered to be fair (reflected by the average fair take rate being lower than the average expected take rate). A casual look at the scatter plot of the fair and expected take rates (see Figure 4) seems to indicate that indeed the fair take rate functions as a lower bound for the expected take rate. Further support for this idea is provided by the fact that an almost identical pattern is seen if we look at the relationship between the take rate chosen by proposers and the take rate proposers considered as fair (only $10.2 \%$ of proposers chose a take rate that was lower than their fair take rate).

\footnotetext{
${ }^{23}$ We get very similar results when we test each treatment separately.
} 
Figure 4: Scatter plot of expected and fair take rates

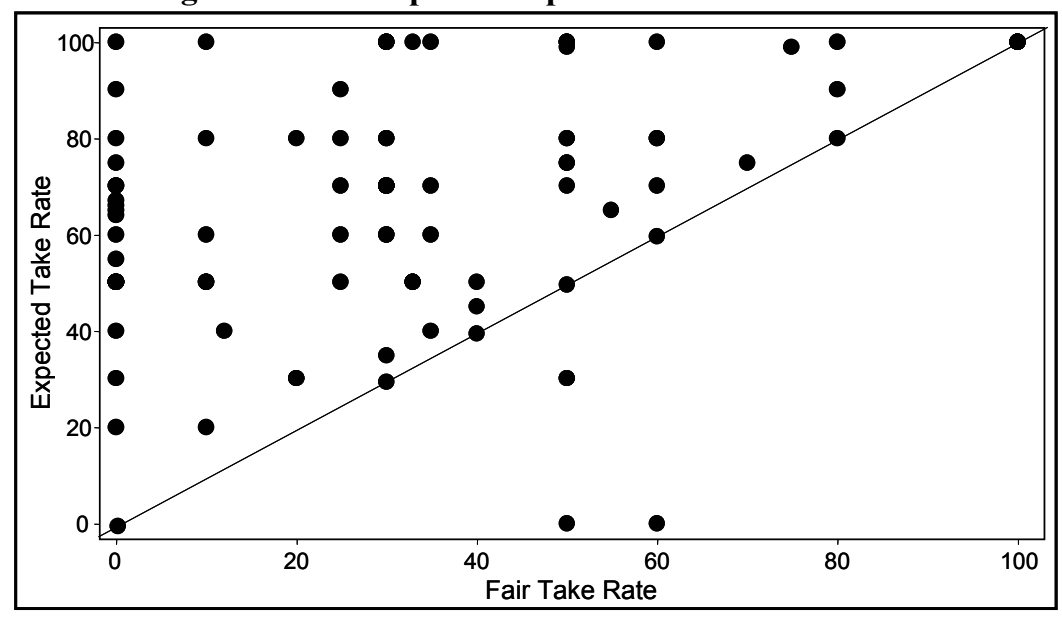

To conclude, it seems that proposers are using the take rate they consider to be fair as a reference point for the determination of the optimal take rate. Similarly, responders may use their fair take rate as a reference point to form an expectation of what the real take rate will be. Once this expectation has been formed, it is the deviation from the expected take rate, and not the fair take rate, that induces responders to destroy.

\section{Discussion}

In this section we discuss our results and relate them to recent modeling attempts to account for reciprocity in decision making. Attention will be concentrated on three important aspects of our results that are either missing or unsatisfactorily modeled in the existing approaches: the importance of reference points, the role of expectations, and the effects of social ties.

\section{Reference points}

Experiments using various kinds of games have demonstrated the willingness of individuals to forgo (or spend) monetary income in order to punish 'unfair' (or 'unkind') behavior (for an overview see Camerer, 2003). The issue of how to model fair behavior has been open to considerable discussion. Roughly speaking there are two approaches, an outcome-based approach and an intention-based approach. In the former, fairness is related to the degree of equality of monetary outcomes (for examples, see footnote 1). In the intention-based approach, individuals are considered unfair, or more precisely unkind, depending on how their choices affect the final outcome of a game and the desirability of this outcome compared to other feasible ones. ${ }^{24}$ Though both approaches have proven to be quite

\footnotetext{
${ }^{24}$ Papers in this approach include Rabin (1993), Dufwenberg and Kirchsteiger (2003), and Falk and Fischbacher (2000) who combine both the outcome-based and the intention-based approaches.
} 
successful in explaining a range of different experimental results, a neglected issue seems to be the income that is taken as a reference point.

If we compare the results of our experiment with the results of experiments that use the related ultimatum game, it is easy to see that any theory that wishes to explain both sets of results will have to take into account the possibility of changing reference points. As reported in Camerer (2003), in ultimatum games the proposers' share of the mean offer is usually between $60 \%$ to $70 \%$ and the share of the median offer is usually between $50 \%$ to $60 \%$. Furthermore, there is barely any destruction (rejection) if the proposer offers to keep less than $60 \%$, while on aggregate about $50 \%$ of the income is destroyed if the proposer offers to keep more than $80 \%$. In our power-to-take game, the mean take rate is $61.6 \%$ and the median take rate is $60 \%$. Moreover, only $4.6 \%$ of the responders' income is destroyed at take rates below $60 \%$, while responders destroyed $55.0 \%$ of their income at take rates above $80 \% .{ }^{25}$ However, the similarity is misleading since in the power-to-take game only the responder's income is at stake. Hence, if one compares the shares of the total income that the proposer walks away with, it is much higher in the power-to-take game than in the ultimatum game.

These results are incompatible with all the theories using an outcome-based approach. ${ }^{26}$ These theories assume that people dislike unequal distributions of income. In the ultimatum game, the more a proposer cares about income differences the more likely it is that she will make a generous offer to the responder. Hence, if we increase the endowment of the proposer relative to the endowment of the responder (as we do in the power-to-take game) one should observe on average lower take rates. Since in ultimatum games about half of the subjects offer a fifty-fifty split, the percentage of 'fair minded' subjects is usually thought to be around that number. ${ }^{27}$ For this reason, it is striking that in our experiment, even though proposers could offer a fifty-fifty split by choosing a take rate of $0 \%$, none actually choose to do so. ${ }^{28}$ This large difference between the two games is hard to explain by any theory assuming that subjects are focusing on the experiment's total income distribution.

\footnotetext{
${ }^{25}$ The results of the one-responder power-to-take game investigated by Bosman et al. (2004) show a mean (median) take rate of $59.9 \%(60 \%)$, while $7.5 \%(58.3 \%)$ of the responders' income is destroyed at take rates below $60 \%$ (above $80 \%$ ).

${ }^{26}$ This is also true for Falk and Fischbacher (2000) who combine both kinds of approaches.

${ }^{27}$ For example, Fehr and Schmidt (1999) estimate that about of $60 \%$ subjects would prefer an equal split over any other income distribution.

${ }^{28}$ Also in other power-to-take experiments the number of proposers choosing a take rate of $0 \%$ is smaller than 10\% (Bosman and van Winden, 2002, Bosman et al., 2004).
} 
In this respect, the intention-based approach performs better than the outcome-based approach. In these models, individuals use a fairness benchmark that depends solely on feasible outcomes. More specifically, it depends on how the take rate affects the responder's payoff in comparison to the highest and lowest payoff the responder could get. Since the responder's possible payoffs are not affected by any additional income the proposer might have, these models do not predict that proposers will choose lower take rates in the power-totake game.

\section{Expectations about what happened}

Our experimental results indicate that a responder's expected take rate is an important explanatory variable of whether she destroys or not. From a psychological point of view it is indeed to be expected that someone would feel higher intensities of emotions such as anger and disappointment in the case of high expectations that were proved wrong as opposed to the case of low expectations that were confirmed (Ortony, Clore, and Collins, 1988). Nonetheless, this simple and intuitive reaction is not modeled in either the outcome-based or the intention-based approach.

In the outcome-based approach expectations are not modeled at all. That is to say, in these models, once responders observe what the take rate is, the take rate they expected is no longer relevant. Hence, in these models responders who destroy differ from responders who do not destroy only in how much they care for payoff differences. In other words, their preferences differ. Since we generally think of these preferences as fixed (at least in the shortrun), we might tend to think that there are types of individuals (such as selfish or fair-minded) that will behave as such across games and time. Furthermore, individual behavior would be less susceptible to manipulation through framing or by observing others. If on the other hand, expectations explain a large part of the heterogeneity we observe in experiments, we should be much more careful in predicting how subjects will behave across games and time. ${ }^{29}$ It would also imply that framing or information that affects expectations can have a big impact on the behavior of individuals. From that perspective, an interesting question for future research is what would happen if the game were repeated. Expectations, unlike preferences,

\footnotetext{
${ }^{29}$ We do not dismiss the possibility of consistent differences between people based on how strongly they feel about fairness norms or payoff differences. However, our results suggest that they can explain only a small part of responders' behavior.
} 
may change substantially even in a short period of time. Hence, behavior might adjust much faster than a model based solely on preferences would predict. ${ }^{30}$

In the intention-based approach, which uses psychological game theory (Geanakoplos et al., 1989), expectations play an important role, but not in the way we have discussed here. As in the outcome-based approach, in these models once a responder observes the take rate, her expected take rate has no longer an effect on her decision. The only expectation that has an effect is the responder's expectation of what the take authority expects the destruction rate to be (which determines the kindness of the take authority's choice). Furthermore, in these models attention is focused on equilibria when individuals correctly anticipate the actions of others. However, this raises the question to what extent these models capture experienced emotions.

Some of our results are in line with the theoretical predictions of the models of Rabin (1993) and Dufwenberg and Kirchsteiger (2003). For instance, we find that even when expectations are fulfilled, people that faced high take rates (more unkindness) experienced higher intensities of anger, irritation, envy, and disappointment, and lower intensities of joy and admiration. ${ }^{31}$ The reason is that the intensity of emotions does not only depend on the degree of unexpectedness of an event, but also on the extent to which the individual's interests are affected (see e.g. Ortony et al., 1988), which relates to the take rate as such. More research is needed, though, to see whether this effect survives in the longer run. With experience, people not only learn to anticipate what others will do, they may also habituate to situations and may gradually become less emotional about anticipated adverse events.

Although fulfilled expectations might be a plausible assumption for the long-run, in many situations there is simply not enough time to learn what others will do. In these circumstances, understanding the emotional reactions to deviations from expected actions might prove very useful for predicting how individuals will behave. Furthermore, in cases in which the final outcome is heavily influenced by the initial situation, emotions experienced when expectations are still unfulfilled can have a crucial effect on long-run behavior.

\footnotetext{
${ }^{30}$ For example, one would expect that if a responder consistently sees high take rates, she will eventually update her expectation upwards. In such a case, assuming that the observed relationship between expectations and emotions holds over time, one might observe less destruction. However, this might be a too strong assumption since emotions may build up over time. As people get angrier, smaller deviations from the expected take rate may suffice to induce destruction.

${ }^{31}$ RRO tests $(p<0.10)$, where "high take rates" are defined as take rates above or equal to the median and "fulfilled expectations" means that the expected take rate equaled the actual take rate (within a range of plus or minus 5\%).
} 
Moreover, emotions may have an additional and lasting effect since they can also affect the way individuals learn from experiences (Bower, 1992) and therefore affect the path through which the long-run outcome is obtained.

\section{Social Ties}

As shown in the previous section, social ties can have a considerable impact on behavior. Not only did friends react differently to higher take rates, their emotional reaction towards one another was also very different. However, none of the models discussed so far incorporate an effect of social ties. Doing so might be important since not all meaningful economic interaction occurs between strangers. ${ }^{32}$

In our experiment, angry friends managed to coordinate destruction much more frequently than angry strangers. If we consider the emotional reactions between responders, as discussed with Result 7, this is not surprising. Note that angry strangers who intend to destroy their income face a situation akin to a collective action problem. Our findings suggest that they would like to see the take authority punished but want to avoid being the player in the game that is left with the lowest payoff. We do not know the precise amount of satisfaction that subjects derive from each of the possible outcomes. Nevertheless, judging by the responders' emotional reactions, it would not be farfetched to model the angry strangers' situation as a prisoner's dilemma or a stag hunt game. In either case, destruction is unlikely. ${ }^{33}$ In contrast, in the angry friends case, the observed desire of responders to coordinate on the same action combined with an impulse to destroy makes their situation noticeably different. Angry friends can be modeled as playing a coordination game in which destruction not only gives them the highest payoff but is also the risk-dominant choice, and hence, the most attractive option.

We will discuss two natural ways of allowing for social ties in the two modeling approaches. The first way is to assume that friends are better than strangers at predicting what the other responder will do. The second way is to assume that friends, as opposed to strangers, care for each other's utility.

In the outcome-based approach, knowing what the others will do translates to friends knowing each other's preferences. This might indeed lead to a situation in which strangers

\footnotetext{
${ }^{32}$ In cases such as interaction at the work floor, informal credit institutions, scientific research, and political participation, more interaction might actually occur between friends than between strangers.

${ }^{33}$ This is certainly true for the prisoners' dilemma. In the stag hunt game, destroying is the risk-dominated action and hence less likely, especially if subjects are risk adverse.
} 
destroy less than friends. To see this, note that if the income difference between two responders is indeed important, responders will wish to destroy similar amounts. In this case, uncertainty about the other's preferences makes a responder's destruction decision much more difficult. If, as suggested by Fehr and Schmidt (1999), individuals prefer advantageous inequality to disadvantageous inequality, then destroying less becomes more attractive since it gives a higher payoff if responders fail to coordinate. Hence, since strangers face more uncertainty about the other's actions, on average, they will be likely to destroy less than friends. Nonetheless, this line of thought fails to describe one important aspect of the data, namely that the difference between friends and strangers only occurs at high take rates. In the outcome-based approach, at high take rates the main concern of responders is to lower the income difference between them and the proposer. ${ }^{34}$ Hence, under these conditions both friends and strangers would destroy very similar amounts.

Assuming that friends care for each other's utility might be a more promising way for the outcome-based approach to explain why friends destroy more than strangers when facing high take rates. If responders care for the utility of the other responder, they will not only mind that the proposer has more income than they do, but they will also mind that the proposer has more income than their friend. This leads to a stronger desire to destroy, even at high take rates. In this respect, investigating the precise effect of an interdependent utility function might prove a fruitful line of research.

In the intention-based approach, knowing better what the other responder will do does not affect behavior. The reason is that, in all the models within this approach, individuals care about each other's income only if they can affect it through their actions. Since in the game we used responders cannot affect each other's income, these theories predict that knowing what the other responder will do has no effect on behavior. Therefore, as with the outcomebased approach, a more helpful way of incorporating social ties might be to assume that friends care for each other's wellbeing. In the current models, an individual evaluates the kindness of others by looking at how their actions lead to a higher or lower payoff for the individual. The friends case could be modeled by allowing individuals to include into their evaluation the way others treat the individual's friends. Unfortunately, due to the complexity of these models an interdependent utility function might produce a model that is too difficult to analyze.

\footnotetext{
${ }^{34}$ Due to the high take rate the other responder has little income anyway and destruction will only create small income differences between responders.
} 


\section{Conclusion}

An important goal of this paper was to extend the explicit study of the influence of emotions on economic decision-making to cases with more than two players. In addition, we looked at how social ties can affect emotional reactions and behavior. For this purpose we used a threeperson power-to-take game. The experimental data demonstrate that high intensities of angerlike emotions and low intensities of joy-like emotions induce individuals to destroy their income. We also find that friends and strangers as responders experience different emotional reactions towards one another, which leads to more destruction in the case of angry friends.

Our results indicate that the study of emotions helps explain observed behavior. Angerlike emotions appeared to be the main driving force behind the decision to destroy income. Furthermore, by observing the emotional reaction between subjects we could explain why friends are able to coordinate on destruction more frequently than strangers. Without investigating these emotional responses, the precise mechanism by which social ties affected the subjects' choices would have remained unclear.

In this paper we have also emphasized the role of expectations in determining the subjects' emotional responses. One interesting issue for future research concerns the interaction between expectations and social norms. If social norms are based on the actual behavior of the majority of individuals in a society, then expectations may be largely fulfilled in many well established situations. However, when faced with new circumstances in which a social norm is not clearly defined, the initial expectations of individuals might have an important effect on the behavior that later becomes a norm. Hence, norms might be very susceptible to the initial conditions in which they are formed.

In addition to expectations, we would like to emphasize the importance of studying social ties. Our experiment showed clear differences in emotional reactions depending on the type of social tie. In some situations this could lead to very different behavior that might be economically relevant. For example, it might help determine what kind of jobs are better for work in groups and which are more suited for individual work. Understanding the behavioral differences induced by social ties could prove especially important if one is thinking on the effectiveness of various policies. It might be the case that a given policy would improve a situation only if individuals (do not) share social ties. Investigating the emotional responses may reveal the precise mechanism through which social ties affect the subjects' choices and could therefore help us predict the effect of a policy. To give an example, the emotional responses of friends indicate a strong desire to coordinate their actions. In this case a 
coordination mechanism such as the possibility to communicate might be more effective among friends than among strangers.

So far, the effects of social ties have received little attention in experimental investigations. To some extent, this neglect is due to the difficulty of creating strong social ties in controlled environments. The usual ingredients of complete anonymity, no face-to-face communication, and a short time period of interaction, produce an environment in which meaningful social bonding is rather difficult. Nevertheless, the design we have used suggests that it is possible to include social ties in experiments and to acquire insights into how to model them. 


\section{Appendix 1 - Instructions}

These are the instructions for the 'friends' treatment. The instructions for the 'strangers' treatment were very similar, and are available upon request.

\section{Instructions (translation from Dutch)}

In order to sign up for this experiment, you had to sign up together with a second participant. For convenience, we will refer to this second participant as your partner. In the experiment each of you will be assigned to a 3-person group, that is, you plus two other participants. We will explain how groups are formed later on.

Throughout the experiment, the type of decision you make will depend on your position in your group. Some of you will be positioned to move first, and some of you will be positioned to move second. Participants moving first will be referred to as As while participants moving second will be referred to as Bs.

Before the experiment started each desk was assigned either an A or a B. Therefore, by randomly assigning the yellow cards [in the reception room], each participant was randomly assigned a position. Once you are informed which position has been assigned to you, the corresponding letter will appear on the top-right part of the screen.

The 3-person group that you belong to depends on your position as well as on the position of others in the following way:

- Your group (including yourself) consists of one A and two Bs.

- If you are a B:

○ Then, the other B in your group is your partner (the person with whom you signed up).

○ The other participant will be a randomly chosen A.

- If you are an A:

○ Then your partner (the person with whom you signed up) is also an A and thus he/she is not in your group.

○ The other two participants will be a randomly selected pair of Bs that signed up together for the experiment.

Note: Each group, and thus also your group, was formed randomly in the sense that the $\mathrm{A}$ in the group does not know who the B's are, and similarly the B's do not know who the A is.

\section{The experiment}

At the beginning of the experiment each participant - this includes all A participants and all B participants - will receive 10 euros as his/her initial endowment. The experiment consists 
of two phases. In phase one, only the A participant must make a decision. Similarly, in phase two, only the B participants must make a decision. Hence, every participant makes only one decision. In addition to the decision, during the experiment you will be asked to answer a few questions.

\section{Phase one: A chooses a percentage}

In this phase, A must choose a percentage and type it into the corresponding field on the screen. This percentage determines how much of the money of each B in the group after phase two, will be transferred to A. The percentage chosen by A must be an integer between 0 and 100 (inclusive). If you wish to make any calculations, you can use the calculator located on your desk.

Once you are satisfied with your decision, you have to confirm it by clicking on the button "Ready". Note that all decisions are final; once you have clicked on "Ready" there is no way of changing your choice. Once A has completed phase one, phase two begins.

Phase two: each B chooses a percentage

At the beginning of this phase, each B is informed of the percentage chosen by A. At this point, each B must also choose a percentage and type it into the corresponding field on the screen. This percentage determines how much of his/her initial endowment will B destroy. The percentage chosen by B must be an integer between 0 and 100 (inclusive). Hence, the transfer from each participant B to participant A will be based on the endowment of B that is left.

Once you are satisfied with your decision, you have to confirm it by clicking on the button "Ready". Note that all decisions are final; once you have clicked on "Ready" there is no way of changing your choice. Once each person has made his/her decision, phase two ends.

Payoffs

After phase two, all participants will be informed of the amount of money they have earned during the experiment. You will also be informed of the amount of money earned by the other two participants in your group.

\section{Example of how to calculate your payoffs}

We will now give an example for the purpose of illustration. Remember that all participants in your group have an initial endowment of 10 euros. Suppose that in phase one participant A decides that $30 \%$ of the endowment of each participant B will be transferred to him/her (participant A). In phase two, each B can destroy part or everything of his/her initial endowment. Suppose that both Bs decide to destroy $0 \%$ percent of their initial endowment. 
The transfer from each B to A is then equal to 3 euros (30\% of 10 euros). The earnings of each $B$ are equal to 7 euros (namely, the initial endowment of 10 euros minus the transfer of 3 euros). The final endowment of $\mathrm{A}$ is equal to 16 euros (namely, the initial endowment of 10 euros plus twice a transfer of 3 euros).

Now suppose that in this example, one of the B participants decides to destroy $50 \%$ of his/her initial endowment. In this case, his/her transfer to A is only 1.5 euros (namely, $30 \%$ of the endowment that was not destroyed, i.e. is $30 \%$ of 5 euros). The earnings of A are equal to 14.5 euros (namely, the initial endowment of 10 euros plus 3 euros transferred from the B who destroyed $0 \%$ plus 1.5 euros transferred from the B who destroyed 50\%). The earnings of the $\mathrm{B}$ who destroyed $0 \%$ are again 7 euros, and, finally, the earnings of the $\mathrm{B}$ who destroyed $50 \%$ are 3.5 euros (namely, $50 \%$ of the initial endowment of 10 euros minus the transfer of 1.5 euros).

In summary

In the experiment you will be divided into groups of 3, each consisting of one A and two Bs (who signed up together for the experiment). The roles of A and B where randomly and anonymously assigned by drawing your table number. Each participant receives 10 euros as an initial endowment. Then there are two phases. In phase one, A decides on a percentage that indicates how much of the endowments of each B after phase two will be transferred to A. In phase two, each $\mathrm{B}$ decides what percentage of his/her initial endowment will be destroyed.

If you have any questions now, please raise your hand. If you do not have any questions, please click on "Ready". Note that once you click on "Ready" you will not be able to go back to the instructions. Next, we will ask you to answer a few questions in order to familiarize you with the calculation of your earnings. 


\section{Appendix 2 - Summary of individual data}

Table 3: Take and destruction rates by group and treatment

\begin{tabular}{|c|c|c|c|c|c|c|}
\hline \multirow[b]{2}{*}{ Group \# } & \multicolumn{3}{|c|}{ Friends } & \multicolumn{3}{|c|}{ Strangers } \\
\hline & $t$ & $d_{1}$ & $d_{2}$ & $t$ & $d_{1}$ & $d_{2}$ \\
\hline 1 & 29 & 0 & 0 & 30 & 0 & 0 \\
\hline 2 & 33 & 0 & 0 & 30 & 0 & 0 \\
\hline 3 & 35 & 20 & 0 & 30 & 0 & 0 \\
\hline 4 & 40 & 0 & 0 & 38 & 0 & 0 \\
\hline 5 & 40 & 0 & 0 & 40 & 0 & 0 \\
\hline 6 & 40 & 0 & 0 & 45 & 0 & 10 \\
\hline 7 & 40 & 0 & 0 & 50 & 0 & 0 \\
\hline 8 & 40 & 0 & 0 & 50 & 0 & 100 \\
\hline 9 & 42 & 0 & 0 & 50 & 0 & 0 \\
\hline 10 & 45 & 0 & 0 & 60 & 0 & 0 \\
\hline 11 & 46 & 5 & 0 & 60 & 0 & 40 \\
\hline 12 & 50 & 0 & 0 & 60 & 20 & 20 \\
\hline 13 & 50 & 0 & 0 & 60 & 50 & 0 \\
\hline 14 & 50 & 0 & 0 & 65 & 0 & 0 \\
\hline 15 & 50 & 0 & 0 & 65 & 10 & 100 \\
\hline 16 & 50 & 5 & 0 & 68 & 10 & 0 \\
\hline 17 & 55 & 100 & 0 & 68 & 100 & 0 \\
\hline 18 & 60 & 0 & 0 & 70 & 0 & 0 \\
\hline 19 & 60 & 0 & 0 & 70 & 0 & 0 \\
\hline 20 & 60 & 0 & 25 & 75 & 50 & 0 \\
\hline 21 & 60 & 20 & 0 & 75 & 100 & 75 \\
\hline 22 & 65 & 0 & 50 & 95 & 0 & 0 \\
\hline 23 & 65 & 25 & 0 & 99 & 0 & 99 \\
\hline 24 & 65 & 50 & 0 & 100 & 0 & 100 \\
\hline 25 & 70 & 100 & 0 & & & \\
\hline 26 & 80 & 20 & 100 & & & \\
\hline 27 & 80 & 100 & 0 & & & \\
\hline 28 & 90 & 0 & 100 & & & \\
\hline 29 & 90 & 90 & 100 & & & \\
\hline 30 & 100 & 50 & 100 & & & \\
\hline 31 & 100 & 100 & 100 & & & \\
\hline 32 & 100 & 100 & 100 & & & \\
\hline 33 & 100 & 100 & 100 & & & \\
\hline 34 & 100 & 100 & 100 & & & \\
\hline 35 & 100 & 100 & 100 & & & \\
\hline
\end{tabular}

Where: $t=$ take rate, $d_{i}=$ destruction rate of responder $i$. 
Table 4: Mean emotional intensity of responders regarding the take authority

\begin{tabular}{|c|c|c|c|c|}
\hline & \multicolumn{2}{|c|}{ Friends } & \multicolumn{2}{c|}{ Strangers } \\
\hline Emotions of $\boldsymbol{i}$ & $\boldsymbol{d}_{\boldsymbol{i}}=\mathbf{0}$ & $\boldsymbol{d}_{\boldsymbol{i}}>\mathbf{0}$ & $\boldsymbol{d}_{\boldsymbol{i}}=\mathbf{0}$ & $\boldsymbol{d}_{\boldsymbol{i}}>\mathbf{0}$ \\
\hline admiration & $2.7(1.9)$ & $1.3(0.7)$ & $2.5(1.8)$ & $2.1(1.6)$ \\
anger & $2.3(1.6)$ & $4.1(2.2)$ & $2.9(1.9)$ & $4.2(1.7)$ \\
contempt & $2.2(1.7)$ & $4.5(2.2)$ & $2.6(1.9)$ & $4.0(1.9)$ \\
disappointment & $2.7(1.7)$ & $4.3(2.1)$ & $3.2(2.1)$ & $5.1(1.5)$ \\
envy & $3.3(1.7)$ & $3.7(2.3)$ & $2.9(1.9)$ & $4.6(1.2)$ \\
gratitude & $3.5(2.1)$ & $1.5(0.9)$ & $2.9(2.0)$ & $1.7(1.4)$ \\
guilt & $1.4(0.9)$ & $1.4(0.8)$ & $1.5(1.1)$ & $1.7(1.3)$ \\
irritation & $2.9(1.9)$ & $5.2(2.1)$ & $3.1(2.1)$ & $4.5(2.0)$ \\
joy & $3.6(2.0)$ & $1.6(1.3)$ & $3.0(2.0)$ & $1.9(1.3)$ \\
pride & $2.3(1.4)$ & $2.8(2.3)$ & $2.3(1.7)$ & $2.9(1.9)$ \\
regret & $1.4(1.0)$ & $1.6(1.2)$ & $1.6(1.3)$ & $1.7(1.2)$ \\
sadness & $1.6(1.1)$ & $2.2(1.5)$ & $1.7(1.5)$ & $2.4(1.4)$ \\
shame & $1.4(0.9)$ & $1.6(1.3)$ & $1.2(0.8)$ & $1.9(1.7)$ \\
surprise & $4.0(2.1)$ & $4.5(1.9)$ & $3.5(2.3)$ & $3.4(1.5)$ \\
\hline
\end{tabular}

Numbers between brackets are standard deviations.

Table 5: Mean emotional intensity of responders regarding the other responder

\begin{tabular}{|c|c|c|c|c|c|c|}
\hline & \multicolumn{3}{|c|}{ Friends } & \multicolumn{3}{c|}{ Strangers } \\
\hline Emotions of $\boldsymbol{i}$ & $\boldsymbol{d}_{\boldsymbol{i}}>\boldsymbol{d}_{\boldsymbol{j}}$ & $\boldsymbol{d}_{\boldsymbol{i}}=\boldsymbol{d}_{\boldsymbol{j}}$ & $\boldsymbol{d}_{\boldsymbol{i}}<\boldsymbol{d}_{\boldsymbol{j}}$ & $\boldsymbol{d}_{\boldsymbol{i}}>\boldsymbol{d}_{\boldsymbol{j}}$ & $\boldsymbol{d}_{\boldsymbol{i}}=\boldsymbol{d}_{\boldsymbol{j}}$ & $\boldsymbol{d}_{\boldsymbol{i}}<\boldsymbol{d}_{\boldsymbol{j}}$ \\
\hline admiration & $3.1(2.2)$ & $3.8(1.9)$ & $3.1(2.2)$ & $2.5(1.8)$ & $2.5(1.9)$ & $3.6(2.5)$ \\
anger & $2.3(2.3)$ & $1.1(0.3)$ & $1.6(1.0)$ & $2.8(1.6)$ & $1.0(0.2)$ & $1.5(1.2)$ \\
contempt & $1.7(1.3)$ & $1.1(0.3)$ & $1.3(0.7)$ & $3.7(2.0)$ & $1.0(0.2)$ & $1.2(0.4)$ \\
disappointment & $2.6(2.4)$ & $1.1(0.3)$ & $1.6(1.1)$ & $3.2(1.9)$ & $1.0(0.2)$ & $1.3(0.6)$ \\
envy & $2.3(2.1)$ & $1.1(0.3)$ & $1.5(1.1)$ & $2.5(1.2)$ & $1.1(0.3)$ & $1.3(0.6)$ \\
gratitude & $2.7(2.1)$ & $3.2(2.1)$ & $2.0(1.3)$ & $2.7(1.8)$ & $2.0(1.5)$ & $2.7(1.8)$ \\
guilt & $1.5(1.1)$ & $1.2(0.8)$ & $1.4(0.9)$ & $1.9(1.4)$ & $1.0(0.2)$ & $1.6(1.1)$ \\
irritation & $2.5(2.3)$ & $1.1(0.2)$ & $1.6(1.2)$ & $2.9(2.0)$ & $1.1(0.3)$ & $1.5(1.2)$ \\
joy & $2.6(2.0)$ & $5.0(1.3)$ & $3.2(2.1)$ & $2.7(1.6)$ & $2.8(1.8)$ & $2.9(2.3)$ \\
pride & $3.1(2.1)$ & $4.8(1.9)$ & $2.5(1.9)$ & $4.1(1.7)$ & $2.7(1.8)$ & $2.7(2.2)$ \\
regret & $1.3(0.7)$ & $1.2(0.7)$ & $1.8(1.5)$ & $2.1(1.7)$ & $1.0(0.2)$ & $1.9(1.4)$ \\
sadness & $1.9(1.9)$ & $1.1(0.5)$ & $1.3(0.6)$ & $2.5(1.7)$ & $1.0(0.2)$ & $1.1(0.3)$ \\
shame & $1.9(1.8)$ & $1.1(0.3)$ & $1.9(1.6)$ & $2.2(1.8)$ & $1.0(0.0)$ & $1.6(1.0)$ \\
surprise & $4.7(1.7)$ & $2.1(1.4)$ & $4.1(2.5)$ & $4.5(1.5)$ & $1.6(1.2)$ & $4.5(2.1)$ \\
\hline
\end{tabular}

Numbers between brackets are standard deviations. 


\section{Appendix 3 - Regressions}

Multivariate probit model with the probability of some destruction as the dependent variable $(0=$ no destruction, $1=$ positive destruction $)$ :

Table 6: Probit model estimating the probability of destruction

\begin{tabular}{|l|c|c|}
\hline $\begin{array}{l}\text { Number of obs. }=118 \\
\text { Log likelihood }=-49.0516\end{array}$ & Lrob chi $^{2}(6)=56.69$ \\
\hline Variable & Coefficient & \\
\hline Friends * Take Rate & 0.027125 & p value \\
Strangers * Take Rate & 0.019839 & 0.006 \\
Take Rate - Expected Take Rate & 0.018560 & 0.043 \\
Take Rate - Fair Take Rate & 0.002899 & 0.003 \\
Economist & -0.506895 & 0.640 \\
Female & -0.644031 & 0.105 \\
Constant & -1.484900 & 0.045 \\
\hline
\end{tabular}

Dummy variables: Friends: 1 if friends treatment, 0 otherwise; Strangers: 1 if strangers treatment, 0 otherwise; Economist: 1 if economics student, 0 otherwise; Female: 1 if female, 0 if male.

Multivariate ordered probit model with the average of the three anger-like emotions (anger, irritation, and contempt) as the dependent variable:

Table 7: Probit model estimating the intensity of anger-like emotions

\begin{tabular}{|l|c|c|}
\hline $\begin{array}{l}\text { Number of obs. }=118 \\
\text { Log likelihood }=-195.2334\end{array}$ & $\begin{array}{l}\text { LR chi } \\
\text { Prob }>\text { chi }^{2}=0.0000\end{array}$ \\
\hline Variable & Coefficient & p value \\
\hline Take Rate & 0.0198103 & 0.003 \\
Take Rate - Expected Take Rate & 0.0088965 & 0.023 \\
Take Rate - Fair Take Rate & 0.0043487 & 0.245 \\
Economist & 0.1119274 & 0.585 \\
Female & -0.4166006 & 0.048 \\
Friends & 0.1009306 & 0.615 \\
\hline
\end{tabular}

Dummy variables as in Table 6. 


\section{References}

Abbink, K., B. Irlenbusch, and E. Renner (2002). Group size and social ties in microfinance institutions. Discussion Paper, University of Erfurt.

Ben-Shakhar, G., G. Bornstein, A. Hopfensitz, and F. van Winden (2004). Reciprocity and emotions: Arousal, self-reports, and expectations. Working paper. University of Amsterdam.

Bereby-Meyer, Y. and M. Niederle (2004). Fairness in bargaining. Journal of Economic Behavior and Organization, forthcoming.

Bolton, G. and A. Ockenfels (2000). A theory of equity, reciprocity, and competition. American Economic Review 90: 166-193.

Bosman, R., and F. van Winden (2002). Emotional hazard in a power-to-take game experiment. The Economic Journal 112: 147-169.

Bosman, R., M. Sutter, and F. van Winden (2004). On the impact of real effort and emotions in power-to-take experiments. Journal of Economic Psychology, forthcoming.

Bower, G. (1992). How might emotions affect learning? In Christianson, S.A. (Ed.) Handbook of emotion and memory: Research and theory. Hillsdale: Erlbaum.

Camerer, C. (2003). Behavioral Game Theory. New Jersey: Princeton University Press.

Charness, G. and M. Rabin (2002). Understanding social preferences with simple tests. The Quarterly Journal of Economics 117: 817-869.

Chong, D. (1991). Collective Action and the Civil Rights Movement. Chicago: University of Chicago Press.

Clore, G.L. and M.D. Robinson (2002). Belief and feeling: Evidence for an accessibility model of emotional self-report. Psychological Bulletin 128: 934-960.

Dufwenberg, M. and U. Gneezy (2000). Measuring beliefs in an experimental lost wallet game. Games and Economic Behavior 30: 163-182.

Dufwenberg, M. and G. Kirchsteiger (2003). A theory of sequential reciprocity. Games and Economic Behavior, forthcoming.

Elster, J. (1998). Emotions and economic theory. Journal of Economic Literature 36: 47-74.

Erard, B. and J.S. Feinstein (1994). Honesty and evasion in the tax compliance game. RAND Journal of Economics 25: 1-19.

Falk, A. and U. Fischbacher (2000). A theory of reciprocity. Working paper No. 6. Institute for Empirical Research in Economics, University of Zürich. 
Fehr, E., G. Kirchsteiger, and A. Riedl (1993). Does fairness prevent market clearing? An experimental investigation. The Quarterly Journal of Economics 108: 437-459.

Fehr, E. and S. Gächter (2002). Altruistic punishment in humans. Nature 415: 137-140.

Fehr, E. and K. Schmidt (1999). A Theory of fairness, competition and cooperation. The Quarterly Journal of Economics 114: 817-868.

Fehr, E. and K. Schmidt (2000). Theories of fairness and reciprocity: Evidence and economic applications. In Dewatripont, M., L. Hansen, and S.T. Turnovsky (Eds.) Advances in Economics and Econometrics - 8th World Congress, Econometric Society Monographs. Cambridge: Cambridge University Press.

Feltovich, N.J. (2003). Nonparametric tests of differences in medians: Comparison of the Wilcoxon-Mann-Whitney and Robust Rank-Order Tests. Experimental Economics 6: 273-297.

Fischbacher U. (1999). Zurich toolbox for readymade economic experiments, experimenter's manual. Working Paper No. 21. Institute for Empirical Research in Economics, University of Zürich.

Flinger, M.A. and G.E. Policello (1981). Robust rank procedures for the Behrens-Fisher problem. Journal of the American Statistical Association 76: 162-178.

Frank, R. H. (1987). If Homo Economicus could choose his own utility function, would he want one with a conscience. American Economic Review 77: 593-604.

Frijda, N.H. (1986). The emotions. Cambridge: Cambridge University Press.

Frijda, N.H. (1988). The laws of emotion. American Psychologist 43: 349-358.

Geanakoplos, J., D. Pearce, and E. Stacchetti (1989). Psychological games and sequential rationality. Games and Economic Behavior 1: 60-79.

Glaeser, E. (2004). The political economy of hatred. Working paper. Harvard University.

Goleman, D. (1995). Emotional intelligence: Why it can matter more than IQ. New York: Bantam Books.

Güth W. and E. van Damme (1998). Information, strategic behavior and fairness in ultimatum bargaining: An experimental study. Journal of Mathematical Psychology 42: 227-247.

Hirshleifer, J. (1987). On emotions as guarantors of threats and promises. In Dupre J. (Ed.) Latest on the Best: Essays on Evolutions and Optimality. Cambridge: MIT Press.

Jakobs, E., A.S.R. Manstead, and A.H. Fischer (1996). Social context and the experience of emotion. Journal of Nonverbal Behavior 20: 123-142. 
Jakobs, E., A.S.R. Manstead, and A.H. Fischer (1999). Social motives, emotional feelings, and smiling. Cognition and Emotion 13: 321-345.

Kagel, J.H. and K.W. Wolfe (2001). Tests of fairness models based on equity considerations in a three-person ultimatum game. Experimental Economics 4: 203-219.

Knez, M. and C.F. Camerer (1995). Outside options and social comparison in a three-player ultimatum game experiments. Games and Economic Behavior 10: 65-94.

Lazarus, R.S. (1991). Emotion and Adaptation. New York: Oxford University Press.

Lerner, J.S. and D. Keltner (2000). Beyond valence: Toward a model of emotion-specific influences on judgment and choice. Cognition and Emotion 14: 473-492.

Levine, D. (1998). Modeling altruism and spitefulness in experiments. Review of Economic Dynamics 1: 593-622.

Loewenstein, G.F. (1996). Out of control: Visceral influences on behavior. Organizational Behavior and Human Decision Processes 65: 272-292.

Loewenstein, G. F. (2000). Emotions in economic theory and economic behavior. American Economic Review, Papers and Proceedings 90: 426-432.

Ortony, A., G.L. Clore, and A. Collins (1988). The cognitive structure of emotions. Cambridge: Cambridge University Press.

Pillutla, M.M. and J.K. Murnighan (1996). Unfairness, anger, and spite: Emotional rejections of ultimatum offers. Organizational Behavior and Human Decision Processes 68: 208224.

Quervain, D.J.F., U. Fischbacher, V. Treyer, M. Schellhammer, U. Schnyder, A. Buck, and E. Fehr (2004). The neural basis of altruistic punishment. Science 305: 1254-1258.

Rabin, M. (1993). Incorporating fairness into game theory and economics. American Economic Review 83: 1281-1302.

Riedl, A. and J. Vyrastekova (2003). Responder behavior in three-person ultimatum game experiments. Working paper. University of Amsterdam.

Sanfey, A.G., J.K. Rilling, J.A. Aronson, L.E. Nystrom, and J.D. Cohen (2003). The Neural Basis of Economic Decision-Making in the Ultimatum Game. Science 300: 1755-1758.

Schwarz, N. (1990). Feelings as information: Informational and motivational functions of affective states. In Higgins E.T. and R. Sorrentino (Eds.) Handbook of motivation and cognition: Foundations of social behavior. New York: Guilford Press.

Smith, V.L. (1976). Experimental economics: Induced value theory. American Economic Review 66: 274-279. 
van Winden, F. (2001). Emotional hazard exemplified by taxation-induced anger. KYKLOS 54: 491-506. 